\title{
O CINEMA NA ANÁLISE BENJAMINIANA: DO SEU CARÁTER CATÁRTICO AO IMUNIZADOR.
}

Jorge Luís Carneiro Lopes

\section{RESUMO}

No cenário contemporâneo em que se situa a obra-de-arte, a abordagem de Walter Benjamin sobre a cinematografia realça sua posição especial na moldura da estética de seu tempo. Benjamin vê no cinema um caráter catártico, destruidor, e por isso mesmo, positivo, capaz de se tornar um agente imunizador para aquilo que ele chama de "psicoses de massa". O cinema traz consigo uma "válvula de escape" para um tempo determinado pela opressão da técnica sobre o homem, propiciando um equilíbrio entre homem e aparelho.

Palavras - chave: Walter Benjamin. Cinema. Arte contemporânea. Psicoses de massa. Teor politico.

\section{ABSTRACT \\ THE BENJAMIN'S ANALYSIS FROM MOVIE: FROM CATHARTIC TO IMMUNIZING CHARACTER}

In the contemporary scenario in which the work of art is located, the Walter Benjamin's approach of cinematography enhances his special position in the frame of the of his aesthetics time. Benjamin sees in the movies a cathartic, destructive character, and therefore, positive, able to become an immunizing agent for what he calls "mass psychosis". The film brings a "safety valve" for a certain technique over the oppression of man time, providing a balance between man and machine.

Keywords: Walter Benjamin .Cinema. Modern Art. Mass Psychosis. Political Tenor

\section{INTRODUÇÃO}

Walter Benjamin, filósofo judeu alemão, ficou conhecido pelas reflexões que relacionam estética e política, como uma importante chave para compreensão da Modernidade, na moldura de sua indefinição. A obra de arte sempre representou uma das formas de expressão do homem, através da qual o mesmo objetiva sua interioridade. É de acordo com esse pressuposto que entendemos a singularidade da teoria da arte, na medida em que pode ser mediadora entre o homem e a construção do conhecimento de si mesmo e de sua relação com o outro, a partir do que se pode compreender o sentido 
político lato sensu percebido por Benjamin em uma das interfaces da obra-de-arte enquanto arte.

Nesse sentido, é possível afirmar que a arte está intimamente ligada ao tempo no qual se insere, sofrendo significativamente as influências do momento histórico de modo a ser formulada e reformulada a partir das características essenciais do contexto vivenciado pelo artista. No texto A Obra de arte na era de sua Reprodutibilidade Técnica (1936), Benjamin trata sobre as consequências sofridas pela arte com o advento da sua reprodutibilidade. Tal reprodutibilidade é por sua vez fruto genuíno de um tempo em que a técnica dominou todos os âmbitos da vida, incidindo principalmente nos campos econômico, político e artístico.

Benjamin dá importância especial ao cinema, que considera "a forma de arte correspondente aos perigos existenciais mais intensos com os quais se confronta o homem contemporâneo". ${ }^{1}$ O cinema seria então, a arte que representa a evolução da reprodutibilidade técnica, por ser um estágio avançado dessa reprodutibilidade, constituindo um momento elaborado a ponto de permitir o diálogo intenso entre $\mathrm{o}$ homem, a máquina e a realidade vivenciada, já que

\footnotetext{
A reprodutibilidade técnica do filme tem seu fundamento imediato na técnica de sua produção. Esta não apenas permite, de forma mais imediata, a difusão em massa da obra cinematográfica, como a torna obrigatória. ${ }^{2}$
}

Sobre esse aspecto da teoria benjaminiana, a saber, a situação a que se coloca o cinema na história da reprodutibilidade da arte, bem como do papel político que vai assumir de acordo com Benjamin, buscaremos nos debruçar sobre os fenômenos que possibilitaram a eclosão do filme, entre os quais se destaca a perda da aura da obrade-arte.

\section{A PERDA DA AURA: O CINEMA NO CONTEXTO DA ARTE MODERNA}

N'A obra de arte na era de sua reprodutibilidade técnica, Benjamin elabora uma minuciosa análise da história da arte, sobretudo do ponto de vista do

\footnotetext{
${ }^{1}$ BENJAMIN, 2012, p. 207

${ }^{2}$ BENJAMIN, 2012, p.186
} 
desenvolvimento das técnicas de sua reprodução. É possível perceber nesse texto uma preocupação política, que nos transmite uma posição revolucionária contra o regime que sua época vivenciou - o regime ideológico fascista, como bem expressa Benjamin no início do escrito:

Os conceitos seguintes, novos na teoria da arte, distinguem-se dos outros pela circunstância de não serem de modo algum apropriáveis para os fins do fascismo. Em compensação podem ser utilizados para a formulação de exigências revolucionárias na política artística. ${ }^{3}$

Política artística. Essa poderia ser a expressão usada para caracterizar a intenção de Benjamin, pelo menos enquanto pensador que tem na arte um ponto de partida. Ponto de partida esse que não perde em seu desenvolvimento o teor político, demonstrado principalmente na exposição do poder que o cinema possui, por seu caráter essencialmente difusor, enquanto uma forma de arte que atinge consideravelmente as massas.

Benjamin discorre sobre os diferentes estágios de "evolução" dos modos de reprodução da arte. Desde as considerações tecidas sobre a xilogravura - que representa para ele o momento em que se viu pela primeira vez a possibilidade de reprodução técnica das artes gráficas, ${ }^{4}$ o autor percorre até o momento do advento do cinema, fazendo essa transição por meio da fotografia. Para Benjamin o surgimento da fotografia foi decisivo para a arte, pois "pela primeira vez no processo de reprodução da imagem, a mão foi liberada das responsabilidades artísticas mais importantes, que agora cabiam unicamente ao olho." Mas, ao "liberar a mão das responsabilidades artísticas", não seria o surgimento da fotografia, de certo modo, algo danoso para a arte? Poderíamos considerar um ato propriamente artístico o ato do fotógrafo?

Benjamin observa que o grau avançado de reprodutibilidade traz à arte a perda de seu caráter essencial. Para entender esse caráter é importante compreender o conceito benjaminiano de aura, que define aquilo que a arte, no sentido primitivo, isto é, originário, traz inerentemente, e que lhe é escapado a partir de sua reprodutibilidade.

No seu sentido originário, a arte possui um valor sagrado, único. Ela representa a manifestação primeira da expressividade humana, foi criada num dado

\footnotetext{
${ }^{3}$ BENJAMIN, 2012, p. 180

${ }^{4}$ BENJAMIN, 2012, p. 180

${ }^{5}$ BENJAMIN, 2012, p. 181
} 
momento e num dado lugar. Para Benjamin, o lugar e o momento em que se situa determinada obra, marcam a mesma de forma bastante significativa, atribuindo-lhe uma identidade. Nesse sentido, a obra de arte carrega consigo uma tradição, que constitui o seu âmago. Benjamin observa que:

\begin{abstract}
A forma mais originária de inserção da obra de arte no contexto da tradição se exprimia no culto. As mais antigas obras de arte, como sabemos, surgiram a serviço de um ritual, primeiramente mágico e depois religioso. ${ }^{6}$
\end{abstract}

Ocorre que, com o desenvolvimento da técnica de reprodução, o que era antes uma obra única, dotada de identidade, e de uma essência especial dada pela tradição na qual se inseria, passa agora, através de sua reprodução em larga escala, à condição de simples produto. No afastamento entre a arte e a tradição, isto é, na perda daquilo que Benjamin denomina testemunho histórico, temos a perda da aura de uma obra-de-arte. Assim, “o conceito de aura permite resumir essas características: o que se atrofia na era da reprodutibilidade técnica da obra de arte é a sua aura. Esse processo é sintomático, e sua significação vai muito além da esfera da arte". 7

Uma coisa está clara para Benjamin: "mesmo na reprodução mais perfeita, um elemento está ausente: o aqui e o agora da obra de arte, sua existência única no lugar em que ela se encontra". ${ }^{8}$ Esse elemento (hic et nunc) é dissolvido na produção em massa da obra de arte. Aqui a arte se dissocia de seu valor tradicional, seu valor de culto,"a catedral abandona o seu lugar para instalar-se no estúdio de um amador; o coro, executado numa sala ou ao ar livre pode ser ouvido num quarto". 9

Então, mesmo que a coisa de que se fala (seja a catedral, o coro ou qualquer outra obra de arte) permaneça ainda como obra de arte, deve-se ter em mente que lhe foi tirado, de acordo com Benjamin, seu caráter especial, seu aqui e agora, aquilo que lhe dá autenticidade. Para o autor uma coisa é autêntica quando preserva aquilo que a tradição lhe atribui, na sua origem, como a duração material e o seu testemunho histórico, por exemplo. Portanto, quando a reprodução material em larga escala danifica essa existência única da obra de arte - sua singularidade enquanto arte - danifica também o seu testemunho histórico e com este sua aura.

\footnotetext{
${ }^{6}$ BENJAMIN, 2012, p. 185

${ }^{7}$ BENJAMIN, 2012, p. 182

${ }^{8}$ BENJAMIN, 2012, p. 181

${ }^{9}$ BENJAMIN, 2012, p. 182
} 
Benjamim enfatiza que na medida em que se tem por meio da reprodutibilidade técnica um número expansivo da obra de arte, tem-se simultaneamente uma abrangência massiva dessa mesma obra. Isso se constata com a substituição da existência única da obra-de-arte pela existência massiva. Assim, é gerada uma mudança, ou melhor, um abalo da tradição, que provocará por sua vez, grandes consequências. Tais consequências se baseiam na característica essencial da obra de arte multiplicada pela sua reprodução, a saber, o contato com a grande massa. Mas esse contato abre a possibilidade de educar.

Em contrapartida, a perda da aura e a fuga da tradição sofrida pela obra de arte, movidas pelo processo reprodutor, ao possibilitar uma situação de contato íntimo com os movimentos de massa, "constitui o reverso da crise e renovação atuais da humanidade". ${ }^{10}$ Aqui entra pela primeira vez o papel decisivo do cinema. Para Benjamin, o cinema corresponde ao fator possuidor de maior força relativa a esse processo de "reverso da crise". À arte cinematográfica, o autor alemão atribui um sentido positivo e ao mesmo tempo negativo.

Esses dois sentidos que possui o cinema estão intimamente relacionados, visto que, segundo Benjamin, não se pode conceber o sentido social do cinema sem ter compreendido antes o que ele chama de "lado destrutivo e catártico". Esse caráter destruidor que o cinema possui reside propriamente no seu poder de dissolver o valor tradicional que a cultura atribuiu a seu patrimônio. Percebe-se essa característica na arte cinematográfica através da sua explosão reprodutora de imagens e, junto a elas, também, da obra de arte em geral. A entrar na composição cinematográfica, as artes se fragmentam.

Para compreendermos melhor, basta observar que as obras de antigamente - dotadas de seu aqui e agora, de seu testemunho histórico, sua aura- podem ser facilmente adaptadas e se tornarem obras cinematográficas, passando para isso, é claro, por uma metamorfose. Para isso ocorrerá a perda da aura, o que Benjamin identifica como consequência incidente na tradição, ou no valor tradicional dessa obra dado pela cultura.

\footnotetext{
${ }^{10}$ BENJAMIN, 2012, P. 183
} 
O cinema se insere nesse contexto, uma vez que traz em sua própria essência a reprodutibilidade. Nesse caso, a autenticidade já deixou de ser a produção ou a atuação do intérprete, mas pauta-se agora, sobretudo, nas formas sob as quais a própria ação do ator no momento da gravação é planejada, montada. O caráter artístico então sofre uma mudança, como Benjamin afirma ter ocorrido com a fotografia. Com relação a esta, sob o ponto de vista a partir do qual se analisa o caráter de cópia como fator específico, observa o autor que "no momento em que o critério de autenticidade deixa de aplicar-se à produção artística, toda a função social da arte se transforma. Em vez de fundar-se no ritual ela passa a fundar-se em outra práxis: a política". ${ }^{11}$ Há nesse sentido - na perda do ritual como fundamento, causada pela reprodutibilidade técnica - uma transição para uma esfera nova alcançada pela ruptura ocorrida no conceito de obra-de-arte.

Benjamin aponta que, assim como na pré-história a preponderância do valor de culto numa dada obra de arte fazia com que esta fosse considerada dentro de padrões mágicos, de modo semelhante, nos dias vividos por ele, o fenômeno da reprodutibilidade lhe conferiu um caráter inteiramente diferente. Neste último contexto, o valor de exposição (Ausstellungswert) superou o valor de culto (Kultwert), que a caracterizava ao ser cultuada no interior dos templos e museus - e que exigia sua existência parasitária, isto é, o que possuía feição propriamente "artística", deduz Benjamin, pode ser futuramente considerado como algo ultrapassado.

O paralelo baseado na história da arte, entre o valor pré-histórico que essa assumia em contraposição com o valor atual, lembra que a arte certamente é fruto do tempo, isto é, que leva, em sua aura, o aqui e o agora, e por isso é carregada essencialmente de características tradicionais da sociedade da qual é fruto. Baseados nesse ponto de vista, analisemos, na arte das sociedades pré-históricas, seu valor mágico e ritualístico, que foi ponto de partida para as primeiras manifestações artísticas. Pois bem, "os temas dessa arte eram o homem e seu meio, copiados segundo as exigências de uma sociedade cuja técnica se fundia inteiramente com o ritual". ${ }^{12}$

Uma sociedade onde técnica e ritual se fundem, certamente é algo bem diverso daquilo que Benjamin vivenciou, de modo que na realidade do filósofo em

\footnotetext{
${ }^{11}$ BENJAMIN, 2012, p. 186

12 BENJAMIN, 2012, p. 188
} 
questão eram predominantes valores técnicos independentes do valor de culto. Temos assim um ponto chave, em que Benjamin encontrará no cinema um papel histórico importantíssimo, que confere ao mesmo o seu verdadeiro sentido, nesse novo universo da reprodutibilidade técnica. Com o advento do cinema, trata-se, por outro lado, de uma refuncionalização ${ }^{13}$ da arte, da qual até o início do século XX o mundo estético não se deu conta.

\section{O TEOR POLÍTICO DO CINEMA: DISTINÇÃO ENTRE REPRODUÇÃO FOTOGRÁFICA E CINEMATOGRÁFICA}

Com a cópia, própria à cinematografia, a função social da arte se transforma. O desenvolvimento técnico da sociedade moderna, para Benjamin, constitui algo como uma "segunda natureza", à qual a humanidade está ligada de modo elementar. Esse fenômeno, do qual o homem não possui mais domínio, traz consigo a exigência de um aprendizado. Em favor desse aprendizado o cinema tem algo primordial a transmitir. Benjamin observa que "o filme serve para exercitar o homem nas novas percepções e reações exigidas por um aparelho técnico cujo papel cresce cada vez mais em sua vida cotidiana. Fazer do gigantesco aparelho técnico do nosso tempo o objeto das inervações humanas - é essa a tarefa histórica cuja realização dá ao cinema o seu verdadeiro sentido". ${ }^{14}$ Para definir esses fenômenos que eletrocutam o passante, Benjamin cria o conceito de choque.

A técnica do cinema se distingue da exposição artística. Aqui reside a comparação benjaminiana entre o ator num estúdio cinematográfico, por um lado, e um ator de teatro, por outro. Quanto ao primeiro, o fato de representar diante de uma vasta aparelhagem, o retira do perfil do artista propriamente dito. Enquanto o ator de teatro tem no seu contexto de atuação, diante do público para o qual vai representar uma vez de modo integral, o critério que faz da sua ação uma obra de arte, o mesmo não se passa com o ator cinematográfico.

Há uma semelhança exposta pelo pensador entre o processo de teste no estúdio, que constitui a formação da cena futuramente retratada no cinema, com o

\footnotetext{
${ }^{13}$ BENJAMIN, 2012, p. 190
}

${ }^{14}$ BENJAMIN, 2012, p. 188 
processo de teste profissional realizado especificamente com o advento da mecanização na cadeia de montagem. Em ambos os casos, temos a presença de meios técnicos, diante dos quais deve atuar, na cinematografia, o ator ao fazer a cena, e na tarefa de reunião de cenas realizada pelo operador, uma tarefa semelhante a do operário, na labuta das fábricas, passando por inúmeras provas na cadeia de montagem.

Diante das provas pelas quais passa o operário na cadeia de montagem, o ator de cinema mostra uma característica muito especial na realização do teste cinematográfico. Benjamin explica que essa especialidade do cinema reside em mostrar explicitamente o teste. Isto se dá como um atributo específico da atuação cinematográfica, uma vez que "o intérprete do filme não representa diante de um público, mas de um aparelho". ${ }^{15}$ Assim o filósofo antepõe o homem contra a máquina no embate retratado pelo cinema, embate esse dotado de uma "mostrabilidade" que permite ao ator e ao espectador conservarem, como afirma Benjamin, "a dignidade humana diante do aparelho". 16

A afirmação da dignidade do homem ante os meios técnicos ocorre na forma de bom desempenho que o ator consegue, mesmo intimado pelas exigências dos aparelhos no estúdio e das técnicas cinematográficas. Ela se expressa, e não só se expressa, mas é movida por grande interesse, na medida em que também diante de um aparelho, o espectador "precisa alienar-se de sua humanidade nos balcões e nas fábricas, durante o dia de trabalho". ${ }^{17}$ O que ocorre para Benjamin é que, quando as massas se reúnem nos cinemas, podem ali contemplar "a vingança que o intérprete executa em nome delas". 18

O cinema reflete então o triunfo do homem sobre a máquina, quando o ator, em nome do espectador submisso à mecanização cotidiana, mostra-se dominante enquanto coloca a seu favor o meio técnico. O intérprete cinematográfico possui uma relação especial com as massas já que

Ele [o intérprete] sabe, quando está diante do aparelho, que sua relação é em última instância com a massa. É ela que vai controlá-lo. E ela, precisamente,

\footnotetext{
${ }^{15}$ BENJAMIN, 2012, p. 193

${ }^{16}$ BENJAMIN, 2012, p. 194

${ }^{17}$ BENJAMIN, 2012, p. 194

${ }^{18}$ BENJAMIN, 2012, p. 194
} 
não está visível, não existe ainda, enquanto o ator executa a atividade que será por ela controlada. ${ }^{19}$

Essa relação com as massas, que constitui uma característica inerente ao cinema, representa a importância dessa arte no contexto vivido por Benjamin. Isso o fez atribuir ao cinema um poder especial, ainda não possuído por nenhuma arte precedente. No cinema as pessoas são expostas de certo modo a si mesmas, dado que aquilo que é apresentado na tela reproduz elementos do cotidiano. Além disso, o cinema representa a intervenção realizada no meio, ou melhor, na realidade reproduzida, já que o ator e os demais partícipes da produção cinematográfica intervêm na realidade de modo a modelá-la por conta e vontade própria.

\begin{abstract}
Assim, a apresentação cinematográfica da realidade é para o homem moderno infinitamente mais significativa, porque ela lhe oferece o que temos direito de exigir da arte: um aspecto da realidade livre de qualquer manipulação pelos aparelhos, precisamente graças ao procedimento de penetrar, com os aparelhos, no âmago da realidade. ${ }^{20}$
\end{abstract}

Por um lado, temos no cinema a afirmação do homem (representado na figura do intérprete) sobre a máquina; por outro lado, temos essa exigência de libertação da manipulação da máquina. A força do cinema, derivada de sua difusão possibilita a emergência de um caráter revolucionário peculiar às massas. $\mathrm{O}$ cinema, enquanto parte de um contexto no qual a técnica absorveu completamente a obra de arte, representa ao mesmo tempo uma válvula de escape daquilo a que Benjamin denomina "psicoses de massa". Ao se referir aos perigos que a "tecnização" trouxe às massas, Benjamin observa que essa mesma "tecnização" deixou à humanidade a possibilidade de imunização desses perigos. Segundo ele, essa imunização se dá através de filmes que conseguem "impedir, pelo desenvolvimento artificial de fantasias sadomasoquistas, seu amadurecimento natural e perigoso". ${ }^{21} \mathrm{~A}$ existência do camundongo Mickey, por exemplo, representa a projeção de um "sonho coletivo", em que se pode observar na tela uma existência mágica, livre de determinações naturalmente encontradas pelos homens em seu cotidiano. É quando a articulação místico-poética do aparelho psíquico do homem, na Modernidade, vê a aura antes destinada ao milagre religioso, agora em forma de magia, propiciada, não mais pela fé, mas pela técnica.

\footnotetext{
${ }^{19}$ BENJAMIN, 2012, p. 195

${ }^{20}$ BENJAMIN, 2012, p. 202

${ }^{21}$ BENJAMIN, 2012, p. 205
} 
Portanto, Benjamin vê no cinema uma arte especial, dotada de um caráter revolucionário e positivo, num momento histórico em que a técnica parece cada vez mais oprimir aquilo que é propriamente humano. Diante disso, a arte cinematográfica se faz um fator importantíssimo, pois permite, segundo Benjamin, a criação de um ponto de equilíbrio entre o homem e a máquina, equilíbrio esse capaz de "produzir uma explosão terapêutica do inconsciente". ${ }^{22}$

\section{REFERÊNCIAS}

BENJAMIN, Walter.A obra de arte na era de sua reprodutibilidade técnica (Organização de Márcio Seliggmann-Silva), Tradução: Gabriel Valladão Silva, $1^{\text {a }}$ Edição, Porto Alegre, RS: L\&PM, 2013.

BENJAMIN, Walter A obra de arte na época de sua reprodutibilidade técnica, (Apresentação, tradução e notas de Francisco De Ambrosis Pinheiro Machado), Porto Alegre, RS: Zouk, 2012.

BENJAMIN, Walter. Magia e Técnica, arte e política: Ensaios sobre literatura e história da cultura. Tradução de Sérgio Paulo Rouanet. $8^{a}$ Ed. São Paulo: Brasiliense, 2012 (obras escolhidas, V.I).

BENJAMIN, Walter. Origem do drama trágico alemão. Edição e tradução de João Barrento. Belo Horizonte: autêntica editora, 2011.

CALLADO, Tereza de Castro. "O drama da alegoria no século XVII barroco" in Kalagatos, revista do Mestrado Acadêmico em Filosofia (CMAF), Fortaleza: Eduece, 2004.

GONÇALVES, Renata. Walter Benjamin e a importância do cinema na modernidade. In: "Existência e arte" - revista eletrônica do grupo PET - Ciências Humanas, Estética e Artes da Universidade Federal de São João Del-Rei - Ano IV - janeiro a dezembro de 2008.

KAMBAS, Chryssoulas, "Kunstwerk" in:_BenjaminsBegriffeHerausgegeben von Michael Opitz und ErdmutWizisla, Zweiter Band, Frankfurt am Main: SuhrkampVerlag, 2000.

PENNA, Tiago. O cinema e a percepção sensível. In: Cadernos Walter Benjaminrevista do grupo de pesquisa Walter Benjamin e a Filosofia Contemporâneapublicação periódica — V.02 — janeiro a julho de 2009.

\footnotetext{
${ }^{22}$ BENJAMIN, 2012, p. 205.
} 